\title{
BMJ Assessment of a multimarker strategy Open for prediction of mortality in older heart failure patients: a cohort study
}

\author{
Christian Bjurman, ${ }^{1}$ Juliana Jensen, ${ }^{1}$ Max Petzold, ${ }^{2}$ Ola Hammarsten, ${ }^{3}$ \\ Michael L X Fu ${ }^{1}$
}

To cite: Bjurman C, Jensen J, Petzold M, et al. Assessment of a multimarker strategy for prediction of mortality in older heart failure patients: a cohort study. BMJ Open 2013:3:e002254.

doi:10.1136/bmjopen-2012002254

- Prepublication history and additional material for this paper are available online. To view these files please visit the journal online (http://dx.doi.org/10.1136/ bmjopen-2012-002254).

Received 25 October 2012 Accepted 8 February 2013

This final article is available for use under the terms of the Creative Commons Attribution Non-Commercial 2.0 Licence; see http://bmjopen.bmj.com

\section{${ }^{1}$ Department of Medicine,} Sahlgrenska University Hospital/Östra Hospital, University of Gothenburg, Gothenburg, Sweden ${ }^{2}$ Department of Medicine, Centre for Applied

Biostatistics, University of Gothenburg, Gothenburg, Sweden

${ }^{3}$ Department of Clinical Chemistry and Transfusion Medicine, Institute of Biomedicine, Sahlgrenska Academy, University of Gothenburg, Gothenburg, Sweden

Correspondence to Dr Michael L X Fu; Michael.fu@wlab.gu.se

\section{ABSTRACT}

Objective: Primarily to develop a multimarker score for prediction of 3-year mortality in older patients with decompensated heart failure (HF).

Design: Prospective cohort study.

Setting: Secondary care. Single centre.

Patients and biomarkers: 131 patients, aged $\geq 65$ years, with decompensated HF were included. Assessment of biomarkers was performed at discharge.

Primary outcome measure: 3-year mortality.

Results: Mean age was $73 \pm 11$ years; mean left ventricular ejection fraction , $43 \pm 14 \% ; 53 \%$ were male. The 3-year mortality was $53.4 \%$. The following $\mathrm{N}$-terminal brain natriuretic peptide (NTproBNP) levels could optimally stratify mortality: $<2000 \mathrm{ng} / \mathrm{l}(\mathrm{n}=39)$, $30.8 \%$ mortality; $2000-8000 \mathrm{ng} / \mathrm{l}(\mathrm{n}=58), 51.7 \%$ mortality; and $>8000 \mathrm{ng} / \mathrm{l}(\mathrm{n}=34), 82.4 \%$ mortality. However, in the 2000-8000 ng/l range, NTproBNP levels had low-prognostic capacity, based on the area under the receiver operating characteristic curve (AUC=0.53; $95 \% \mathrm{Cl} 0.40$ to 0.67 ). In this group, multivariate analysis identified age, cystatin C (CysC), and troponin $\mathrm{T}$ (TnT) levels as independent risk factors. A risk score based on these three risk factors separated a high-risk and low-risk groups within the NTproBNP range of 2000-8000 ng/l. The score exhibited a significantly higher AUC $(0.75 ; 95 \% \mathrm{Cl}$ 0.62 to 0.86$)$ than NTproBNP alone $(p=0.03)$ in this NTproBNP group and had similar prognostic capacity as NTproBNP in patients below or above this NTproBNP range $(p=0.57)$. Net reclassification improvement and integrated discriminatory improvement in the group with NTproBNP levels between 2000 and $8000 \mathrm{ng} / \mathrm{l}$ was $54 \%$ and $23 \%$, respectively, and in the whole cohort $22 \%$ and $11 \%$, respectively.

Conclusions: Our results suggested that, to assess risk in $\mathrm{HF}$, older patients required significantly higher levels of NTproBNP than younger patients. Furthermore, a risk score that included TnT and CysC at discharge, and age could improve risk stratification for mortality in older patients with HF in particular when NTproBNP was moderately elevated.

\section{ARTICLE SUMMARY}

Article focus

- Our aim was to develop a multimarker prognostic score for improved risk stratification in decompensated heart failure (HF) in the elderly.

Key messages

- A composite risk score including cystatin C (CysC) over $1.3 \mathrm{mg} / \mathrm{l}$, troponin $\mathrm{T}$ (TnT) over $10 \mathrm{ng} / \mathrm{l}$ and age over 75 years could identify a high-risk and low-risk groups $(p<0.0001)$ for 3 -year mortality in elderly patients with decompensated HF.

- Optimal N-terminal brain natriuretic peptide (NTproBNP) levels for risk stratification in the elderly HF patients were $<2000,2000-8000$ and $>8000 \mathrm{ng} / \mathrm{l}$.

- The risk score could improve risk stratification for mortality in older patients with $\mathrm{HF}$ in particular when NTproBNP was moderately elevated, probably because of moderate NTproBNP elevations caused by other comorbidities.

Strengths and limitations of the study

- We were able to measure levels of multiple biomarkers in a hospital cohort of elderly patients with decompensated HF and assess their association with mortality.

- One potential weakness was that we were unable to include many of the novel biomarkers that are emerging in clinical practice, such as MR-proANP and Copeptin.

\section{INTRODUCTION}

Heart failure (HF) remains as one of the leading causes of death worldwide. ${ }^{1-4}$ With advancing age, the risk increases for HF mortality and associated comorbidity. ${ }^{5-8}$ Previous landmark clinical trials were mostly conducted in younger HF patients who were, on average, under 63 years old. ${ }^{9-11}$ In practice, however, the majority of patients with newonset HF are older adults. ${ }^{12}$ The lack of 
representative samples of older patients in previous clinical trials on $\mathrm{HF}$ has given rise to serious concerns about whether the results from studies on younger patients are relevant for an older population. ${ }^{11} 13$

The risk of death for patients with HF could only be partly explained by established mortality risk factors, including the New York Heart Association (NYHA) functional class, ${ }^{14}$ the N-terminal brain natriuretic peptide (NTproBNP), ${ }^{15}$ and the left ventricular ejection fraction (LVEF) ${ }^{14}{ }^{15}$ This is particularly true for older individuals, where HF often coexists with other lifethreatening diseases. In this context, we hypothesised that NTproBNP alone is not sufficient enough as a prognostic indicator in elderly HF patients and additional biomarkers might have added value in more accurately predicting the prognosis of $\mathrm{HF}$ in older populations.

We have, therefore, evaluated the prognostic potential of NTproBNP with and without other biomarkers in a cohort of older individuals with HF that were admitted because of decompensated HF.

\section{METHODS}

Study cohort and diagnosis

During 2006 and 2007, we consecutively enrolled 131 HF patients aged $\geq 65$ years. The patients were hospitalised because of decompensated HF at the HF Unit, Department of Medicine, Sahlgrenska University Hospital/Sahlgrenska, Gothenburg, Sweden. The diagnosis of HF was based on the European Society of Cardiology definition. ${ }^{16}$ Inclusion criteria were a documented diagnosis of $\mathrm{HF}$ and admitted to hospital because of symptoms, signs or clinical investigations indicating decompensated HF. The only exclusion criteria were not giving informed consent and age $<65$ years.

A patient was defined as having chronic obstructive pulmonary disease (COPD) when an International Classification of Diseases (ICD) code containing J44 was present in the medical record any time prior to discharge, or as having renal failure when any of the ICD codes N18.2-N18.5 were present in the medical record prior to the index admission. The study protocol was approved by the Ethical Committee at the University of Gothenburg. Written informed consent was obtained from all patients, and the study protocol conformed to the ethical guidelines of the 1975 Declaration of Helsinki.

\section{Follow-up and outcomes}

All patients were followed up according to clinical routine. The main outcome was all-cause mortality because older HF patients often die of non-cardiac causes related to comorbidity. Owing to the limited sample size we did not analyse disease-specific mortality. All patients were followed up for 36 months or until death (mean 2.1 \pm 1.2 years). Demographic and clinical information were obtained from medical records, including age, gender, NYHA functional class, LVEF, history of hypertension, ischaemic heart disease and atrial fibrillation.

\section{Echocardiography}

Echocardiography was performed at least once for each patient at the department of clinical physiology in our hospital using the available standard equipment. Echocardiologists were blinded to the biochemical data and the study protocol. LVEF was assessed using Simpson"s Biplane Method and/or by visual assessment. Patients were kept lying in left decubitus position during the examination. No data on interoperator coefficient of variation were available.

\section{Laboratory analysis}

Blood samples were drawn with the patients lying on bed, in the morning on the day of discharge and put in $\mathrm{a}-70^{\circ} \mathrm{C}$ freezer without delay after proper preparation of serum. All serum samples were thawed and analysed in one single run at the Department of Clinical Chemistry at Sahlgrenska University Hospital. Serum NTproBNP was analysed with the Roche Elecsys system with a coefficient of variation (CV) between $3.7 \%$ and $5.0 \%$. Serum cystatin C (CysC) was analysed with reagents from Dako and on Modular P 2551 with a CV between $2.3 \%$ and $4.1 \%$. The values of $\mathrm{CysC}$ were used to calculate the estimated glomerular filtration rate (eGFR) based on a locally generated equation, GFR $\left(\mathrm{ml} / \mathrm{min} / 1.73 \mathrm{~m}^{2}\right)=(85.47 / \mathrm{CysC}(\mathrm{ng} / \mathrm{l}))-9.64$. Troponin $\mathrm{T}(\mathrm{TnT})$ was analysed using fourth-generation assays on a Modular e701 with a limit of detection of $10 \mathrm{ng} / \mathrm{l}$ and a limit of quantification where the CV was below $10 \%$ of $35 \mathrm{ng} / \mathrm{l}$.

All the other laboratory parameters examined were part of the routine laboratory services provided by the Clinical Chemistry Laboratory, Sahlgrenska University Hospital.

\section{Statistical analysis}

Cox regression models were used to evaluate possible associations between mortality and serum levels of biomarkers (NTproBNP, TnT, creatine and CysC) and clinical variables including age, sex, echocardiographic parameters and underlying diseases. Univariate comparisons between groups were calculated with median tests. Dichotomous variables were analysed with the $\chi^{2}$ test. Receiver operating characteristic (ROC) curves were used to assess the prognostic properties of the prognostic score and of different levels of NTproBNP. Areas under the ROC curves (AUCs) were compared with the DeLong methodology. The log rank test was used to compare different strata in Kaplan-Meier analyses of survival. HR with CIs were collected from the outputs from Cox regression analyses. Net reclassification improvement (NRI) and integrated discriminatory improvement (IDI) were calculated using STATA NRI command and STATA IDI command syntax, respectively. In the NRI calculations two risk levels were selected; $>50 \%$ and $<50 \%$ mortality. 
Statistical analyses were performed with SPSS V.19 and Medcalc V.12.1.3.0 or Stata V.12. All probabilities were two-tailed, and $\mathrm{p}<0.05$ were regarded as significant. No missing data existed for the variables included in the prognostic score, but for other tested variables, cases sometimes were excluded if data were missing, although no more than two cases in each analysis had to be excluded because of a high-degree of data availability.

\section{RESULTS}

Demographic and clinical characteristics

In total, 131 older patients with HF were included (table 1). The median age (IQR) was $74(68-79)$ years, the mean
LVEF was $43.1 \pm 13.8 \%$, and $53 \%$ were male (table 1 ). Among the variables, we found that age, NTproBNP, TnT, urea, creatine, CysC and history of renal failure differed significantly between those who died and those who survived over 3 years (table 1 ).

\section{Factors associated with mortality}

Kaplan-Meier plots were used to identify the best separation of three risk groups; low-risk,intermediate-risk,and high-risk groups based on visual appearance and followed by log-rank tests for verification of statistical significance. Total mortality was $53.4 \%$. Patients with NTproBNP levels $<2000 \mathrm{ng} / 1 \quad(\mathrm{n}=39)$ had a significantly

Table 1 Comparisons between those who died and those who survived within 3 years of study initiation

\begin{tabular}{|c|c|c|c|c|}
\hline & All HF patients & Dead & Alive & \\
\hline $\mathbf{n}$ & $\begin{array}{l}131 \\
\text { Median (IQR) }\end{array}$ & $\begin{array}{l}70 \\
\text { Median (IQR) }\end{array}$ & $\begin{array}{l}61 \\
\text { Median (IQR) }\end{array}$ & p Value \\
\hline Male (\%) & $53 \pm 0.50$ & $51 \pm 0.50$ & $56 \pm 0.50$ & 0.57 \\
\hline Age (years) & $74(68-79)$ & $77(72-82)$ & $70(66-75)$ & $p<0.001$ \\
\hline BMI $\left(\mathrm{kg} / \mathrm{m}^{2}\right)$ & $26(23-30)$ & $26(22-29)$ & $27(23-30)$ & 0.89 \\
\hline LVEF (\%) & $45(30-55)$ & $43(29-55)$ & $45(31-55)$ & 0.80 \\
\hline \multicolumn{5}{|l|}{ Lab variables } \\
\hline ALP ( $\mu$ kat/l) & $1.5(1.1-1.9)$ & $1.6(1.2-2.0)$ & $1.4(1.1-1.8)$ & $p=0.49$ \\
\hline ASAT ( $\mu$ kat/l) & $0.5(0.4-0.6)$ & $0.5(0.4-0.7)$ & $0.5(0.4-0.6)$ & $p=0.97$ \\
\hline Bilirubin $(\mu \mathrm{mol} / \mathrm{l})$ & $14(7.6-20)$ & $15(7.4-18)$ & $12(7.7-20)$ & $p=0.35$ \\
\hline UREA (mmol/l) & $11(7.5-14)$ & $13(8.8-17)$ & $9(6.6-12)$ & $p=0.002$ \\
\hline Creatine $(\mu \mathrm{mol} / \mathrm{l})$ & $105(84-136)$ & 115 (93-159) & $94(79-111)$ & $p<0.007$ \\
\hline CRP (mg/l) & $13(2.5-32)$ & $14(2.5-32)$ & $13(2.5-28)$ & $p=0.85$ \\
\hline Haptoglobin (g/l) & $1.4(0.9-2.0)$ & $1.4(0.5-2.0)$ & $1.4(0.9-2.0)$ & $p=0.96$ \\
\hline $\lg G(g / l)$ & $11(9.4-14)$ & $11(8.3-14)$ & $12(9.6-13)$ & $p=0.29$ \\
\hline $\lg M(g / l)$ & $0.74(0.53-1.1)$ & $0.73(0.52-1.2)$ & $0.77(0.55-1.0)$ & $p=0.76$ \\
\hline LDL (mmol/l) & $2.0(1.1-2.9)$ & $1.9(1.4-2.6)$ & $2.1(1.6-2.5)$ & $p=0.28$ \\
\hline Orosomucoid (g/l) & $1.0(0.84-1.4)$ & $1.1(0.9-1.4)$ & $1.0(0.8-1.2)$ & $p=0.42$ \\
\hline $\mathrm{TSH}(\mathrm{mU} / \mathrm{l})$ & $2.0(1.1-2.9)$ & $2.0(1.1-3.1)$ & $1.8(1.0-2.6)$ & $p=0.61$ \\
\hline \multicolumn{5}{|l|}{ Cardiovascular biomarkers } \\
\hline NTproBNP (ng/l) & $4030(1060-8300)$ & 6095 (2555-10 600) & $2270(638-4855)$ & $p=0.002$ \\
\hline $\mathrm{TnT}(\mathrm{ng} / \mathrm{l})$ & $0(0-200)$ & $100(0-400)$ & $0(0-0)$ & $p<0.001$ \\
\hline CK-MB (ng/ml) & $3(3-5)$ & $4(3-5)$ & $3(3-4)$ & $p=0.050$ \\
\hline CysC (mg/l) & $1.3(1.1-1.6)$ & $1.4(1.3-1.8)$ & $1.2(1.1-1.4)$ & $p<0.001$ \\
\hline Adiponectin $(\mu \mathrm{g} / \mathrm{ml})$ & $18(12-30)$ & $20(15-32)$ & $13(11-25)$ & $p=0.43$ \\
\hline \multicolumn{5}{|l|}{ Cardiovascular diseases } \\
\hline Ischaemic heart disease (\%) & $40 \pm 49$ & $44 \pm 50$ & $36 \pm 48$ & $p=0.38$ \\
\hline Valve disease (\%) & $39 \pm 49$ & $37 \pm 49$ & $43 \pm 50$ & $p=0.49$ \\
\hline Hypertension (\%) & $32 \pm 47$ & $28 \pm 45$ & $36 \pm 48$ & $p=0.34$ \\
\hline Diabetes mellitus (\%) & $22 \pm 42$ & $25 \pm 44$ & $18 \pm 39$ & $p=0.31$ \\
\hline Atrial fibrillation (\%) & $42 \pm 50$ & $41 \pm 50$ & $44 \pm 50$ & $p=0.70$ \\
\hline \multicolumn{5}{|l|}{ Comorbidity (\%) } \\
\hline Stroke & $14 \pm 35$ & $14 \pm 35$ & $15 \pm 36$ & $p=0.91$ \\
\hline COPD & $87 \pm 34$ & $14 \pm 35$ & $12 \pm 32$ & $p=0.66$ \\
\hline Renal failure & $6.8 \pm 25$ & $11 \pm 32$ & $1.6 \pm 13$ & $p=0.022$ \\
\hline \multicolumn{5}{|l|}{ Medications (\%) } \\
\hline ACE inhibitors or ARB & $62 \pm 0.49$ & $51 \pm 50$ & $75 \pm 43$ & $p=0.003$ \\
\hline$\beta$-Blockers & $67 \pm 0.47$ & $63 \pm 49$ & $71 \pm 46$ & $p=0.39$ \\
\hline Diuretics & $87 \pm 34$ & $87 \pm 34$ & $87 \pm 34$ & $p=0.94$ \\
\hline
\end{tabular}

ALP, alkaline phosphatase; ASAT, aspartate transaminase; CK-MB, creatine kinase-myocardial band isoenzyme; COPD, chronic obstructive pulmonary disease; CRP, C reactive protein; CysC, cystatin C; hypertension, systolic blood pressure $>140$ and/or diastolic blood pressure $>90$; diabetes, on diabetic medication; IgG, immunoglobulin G; IgM, immunoglobulin M; LDL, low-density lipoprotein; NTproBNP, N-terminal pro-B-type natriuretic peptide; stroke, ischaemic or haemorraghic stroke in the past; TnT, troponin T; TSH, thyroid stimulating hormone. 
(a)

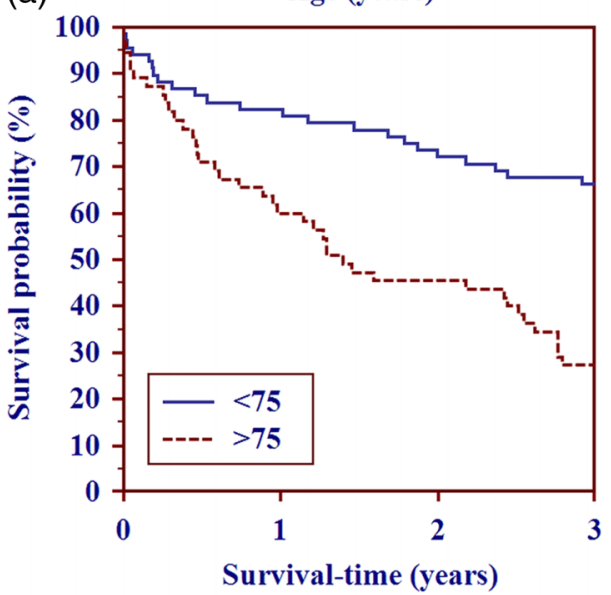

(c)

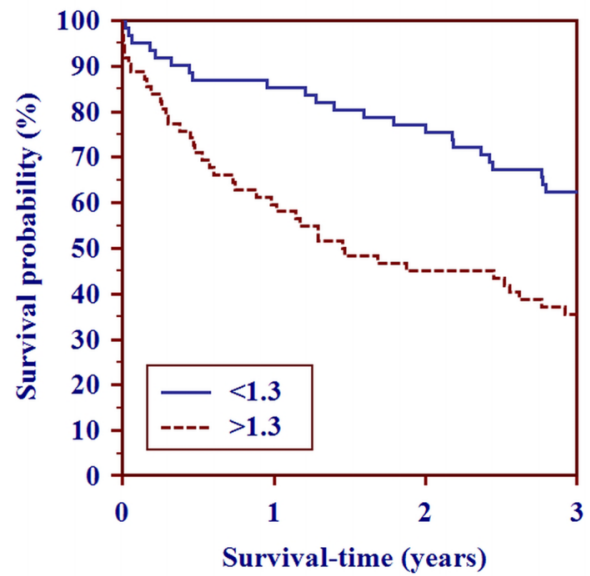

(b) $\operatorname{TnT}(\mathrm{ng} / \mathrm{L})$

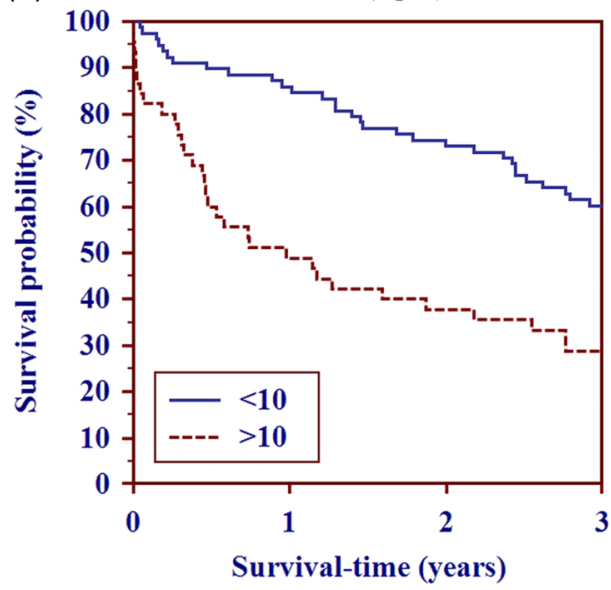

(d)

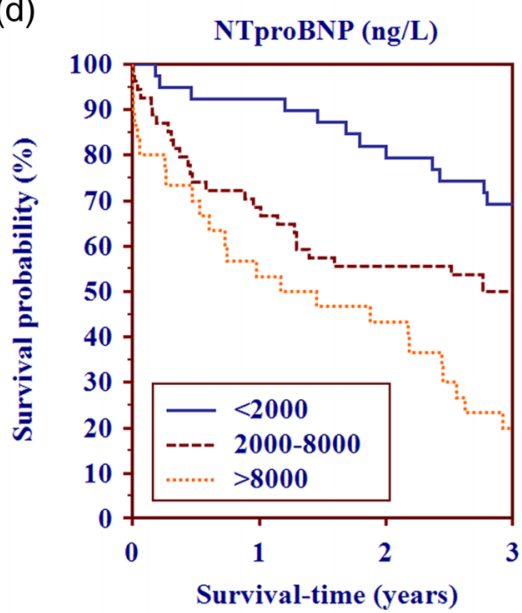

Figure 1 Kaplan-Meier plots show the relationship between 3-year mortality and significant variables (age, troponin T, TnT, and cystatin C, CysC) identified in multivariate analysis (and N-terminal brain natriuretic peptide, NTproBNP) (A-D). p Values for comparisons between strata are shown in table 3 .

better prognosis (30.8\% mortality) compared withpatients with NTproBNP levels in the 2000-8000 range $(\mathrm{n}=58 ; 51.7 \%$ mortality) and patients with NTproBNP levels $>8000 \mathrm{ng} / 1$ ( $\mathrm{n}=34 ; 82.4 \%$ mortality; figure 1$)$.
In univariate regression analyses, age, levels of creatine, NTproBNP, TnT, creatine kinase MB, alkaline phosphatase, urea, CysC and orosomucoid were linked to mortality (tables 2 and 3). However, in multivariate

Table 2 Predictors of death within 3 years of study initiation, assessed with both univariate and multivariate analyses

\begin{tabular}{|c|c|c|c|c|c|c|c|}
\hline \multirow[b]{2}{*}{ Variables } & \multicolumn{4}{|c|}{ Univariate } & \multicolumn{3}{|c|}{ Multivariate } \\
\hline & $\overline{\mathrm{HR}}$ & $95 \% \mathrm{Cl}$ & $\mathrm{X}^{2}$ & p Value & $\overline{H R}$ & $95 \% \mathrm{Cl}$ & p Value \\
\hline Age (years) & 1.06 & 1.03 to 1.09 & 16.0 & $p<0.001$ & 1.06 & 1.02 to 1.09 & 0.002 \\
\hline ALP ( $\mu$ kat/l) & 1.09 & 1.02 to 1.16 & 8.05 & $p=0.010$ & 1.08 & 0.98 to 1.18 & 0.13 \\
\hline UREA (mmol/l) & 1.06 & 1.03 to 1.10 & 14.2 & $p<0.001$ & 0.98 & 0.89 to 1.07 & 0.63 \\
\hline Creatine $(\mathrm{mol} / \mathrm{l})$ & 1.003 & 1.001 to 1.005 & 6.87 & $p=0.011$ & 1.00 & 0.99 to 1.005 & 0.55 \\
\hline Orosomucoid (g/l) & 2.15 & 1.12 to 4.15 & 5.26 & $p=0.022$ & 1.24 & 0.57 to 2.68 & 0.59 \\
\hline NTproBNP (ng/l) & 1.00006 & 1.00004 to 1.00009 & 28.5 & $p<0.001$ & 1.000017 & 0.99997 to 1.00006 & 0.47 \\
\hline $\operatorname{TnT}(\mu \mathrm{g} / \mathrm{l})$ & 2.94 & 1.06 to 8.15 & 4.84 & $p=0.038$ & 147.0 & 11.2 to 1929.8 & $<0.001$ \\
\hline CK-MB (ng/ml) & 1.11 & 1.002 to 1.23 & 4.05 & $p=0.045$ & 0.93 & 0.76 to 1.13 & 0.45 \\
\hline CysC (mg/l) & 2.56 & 1.70 to 3.85 & 20.4 & $p<0.001$ & 6.57 & 1.80 to 24.0 & 0.004 \\
\hline
\end{tabular}


Table 3 p Values for comparisons between strata in Kaplan-Meier plots (figure 1) for 3-year mortality in elderly heart failure patients

\begin{tabular}{lc}
\hline Variable & p Value \\
\hline Age & 0.002 \\
TnT & $<0.0001$ \\
CysC & 0.005 \\
NTproBNP & $<0.001$ \\
\hline
\end{tabular}

CysC, cystatin C; NTproBNP, N-terminal pro-B-type natriuretic peptide; $\mathrm{TnT}$, troponin $\mathrm{T}$.

analyses, only age, $\mathrm{TnT}$ and CysC remained prognostic (table 2).

\section{Composite risk score}

We generated a composite risk score based on the median values of three independent risk factors, age over 75 years $(\mathrm{n}=61)$, TnT over $10 \mathrm{ng} / \mathrm{l}(\mathrm{n}=52)$ and CysC over $1.3 \mathrm{mg} / \mathrm{l}(\mathrm{n}=70)$. The score levels were distributed as follows: 17 patients had 0 points, 49 patients 1 point, 50 patients 2 points and 16 patients 3 points. Each factor represented one point, and the score ranged from 0 to 3 (figure 2). Patients with a score of $0-1$ points had a significantly better survival rate $(79 \%)$ compared withpatients with a score of $2-3$ points $(31 \%$; $\mathrm{p}<0.0001)$ but there was no significant difference between 2 or 3 points (figures 2 and 3). The AUC for predicting 3-year mortality was 0.75 (95\% CI 0.67 to $0.82 ; \mathrm{p}<0.0001)$. When NTproBNP alone was tested as a predictive factor, it generated an AUC in the same range for the entire $\mathrm{HF}$ group, $\mathrm{AUC}=0.72$ (95\% CI 0.64 to $0.80 ; \mathrm{p}=0.58$ ). However, the NTproBNP level did not provide any

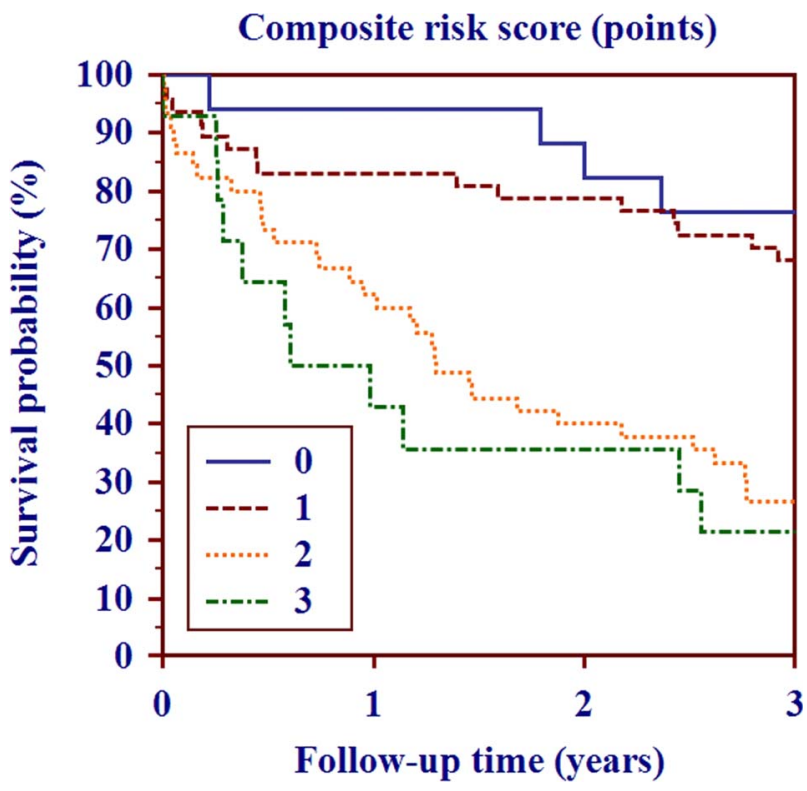

Figure 2 Kaplan-Meier plot shows the relationship between 3 -year mortality and the composite risk factor score $(p<0.0001$ for linear trend).

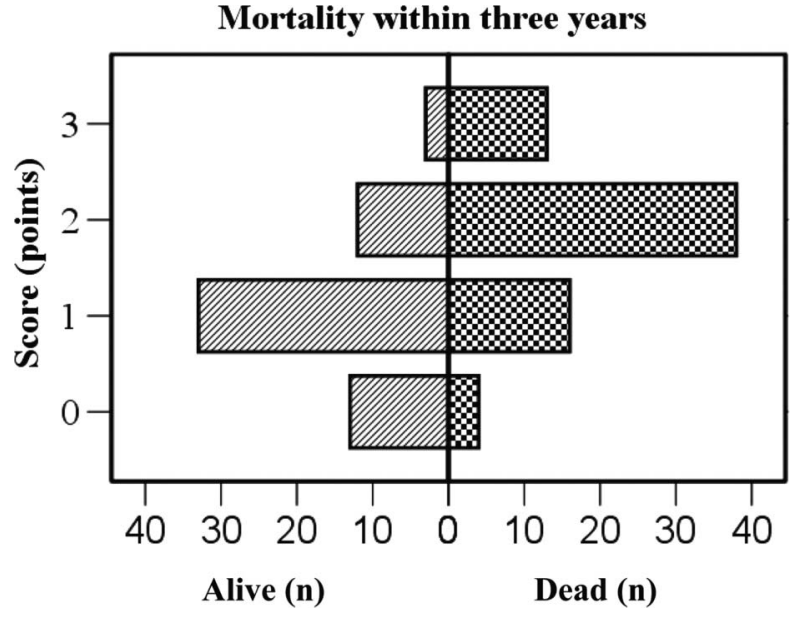

Figure 3 Distribution of the prognostic score among patients who died (right of 0 ) and survived (left of 0 ) within 3 years of inclusion in the study.

graded prognostic information within the range of $2000-8000 \mathrm{ng} / 1 \quad(\mathrm{AUC}=0.53(95 \%$ CI 0.40 to 0.67$))$. In this $\mathrm{HF}$ subgroup the composite risk score improved prognostic assessments $(\mathrm{AUC}=0.75$; $95 \%$ CI 0.62 to 0.86 ; $\mathrm{p}=0.03$ ). Among patients with a NTproBNP level between 2000 and $8000 \mathrm{ng} / 15$ patients had 0 points, 22 patients 1 point, 25 patients 2 points and 6 patients 3 points, thus 27 patients were identified as low-risk (7/27 mortality; $26 \%)$ and 31 patients as high-risk individuals $(23 / 31$ mortality; $74 \%), \mathrm{p}<0.001$. When NTproBNP was above $8000 \mathrm{ng} / \mathrm{l}, 82.4 \%$ of patients died within 3 years, and the score did not add any prognostic information. Among patients with $\mathrm{NTproBNP}<2000$, only $3 \%$ of patients had a composite risk score of $2-3$; thus, the usefulness of the score could not be assessed in this subgroup.

\section{Net reclassification improvement}

Net reclassification improvement after adding the risk score to NTproBNP for improved risk classification (mortality risk above $50 \%$ or below $50 \%$ ) was $54 \%$ in the NTproBNP range $2000-8000 \mathrm{ng} / \mathrm{l}$ and $22 \%$ in the whole cohort.

\section{Integrated discrimination improvement}

Integrated discrimination improvement after adding the risk score to NTproBNP for improved risk classification was $23 \%$ in the NTproBNP range $2000-8000 \mathrm{ng} / \mathrm{l}$ and $11 \%$ in the whole cohort.

\section{DISCUSSION}

This study included a real-life cohort of older patients with $\mathrm{HF}$ and comorbidity. They had been admitted because of decompensated HF. We found that a multimarker strategy could improve risk stratification for mortality within 3 years, in particular in patients with moderately elevated NTproBNP (2000-8000 ng/l). We 
also show that two cut-off values for NTproBNP are useful for identifying high-riskand low-risk individuals. An improved risk assessment would be of great clinical value for more accurately identifying older patients with HF that carries an increased risk of death. These patients should be targeted for more intensive treatment and closer monitoring. As health resources are restricted in the vast majority of the Western countries the need to give priority to high-risk individuals is well-known. Many factors were previously shown to predict adverse outcome in $\mathrm{HF}$, including high age, history of diabetes mellitus or renal dysfunction, high NYHA class, low LVEF, low weight, low systolic blood pressure, the presence of ankle oedema and low quality-of-life scores. ${ }^{17}$ However, a few of those factors are strong prognostic predictors when evaluated separately. Moreover, assessments of those factors are typically difficult in clinical practice, particularly in older patients with comorbidity.

NTproBNP and BNP are important prognostic biomarkers in younger patients with HF. They appear to be better predictors of survival than many traditional prognostic indicators, including the NYHA class, serum creatine and possibly LVEF. ${ }^{14}$ The relative risk of death among younger patients with $\mathrm{HF}$ was shown to increase by about $35 \%$ for each $100 \mathrm{pg} / \mathrm{ml}$ increase in BNP. ${ }^{1418}$ Therefore, BNP or NTproBNP assessments have been emphasised in the European Society of Cardiology guidelines. ${ }^{16}$ However, most prognostic studies that included BNP or NTproBNP assessments were performed in patients whose mean age was under 68 years; ${ }^{14}$ thus, the predictive power of BNP and NTproBNP lack sufficient validation in older patients with $\mathrm{HF}$. The present study indicated that substantially higher levels of NTproBNP should be used for risk stratifications of older patients with HF. For example, NTproBNP levels of $<300 \mathrm{ng} / \mathrm{l}$, $300-1500 \mathrm{ng} / 1$, and $>1500 \mathrm{ng} / 1$ are recommended for stratification of risk based on studies in younger cohorts. $^{16}$ In contrast, in older decompensated HF patients we found that NTproBNP levels of $<2000$, 20008000 and $>8000 \mathrm{ng} / 1$ could optimally separate the HF-cohort into low-risk, moderate-risk and high-risk groups. In agreement with previous studies, ${ }^{19}$ we found that NTproBNP was a significant predictor in univariate, but not in multivariate analyses. This can be explained by the fact that NTproBNP levels are linked to several other factors that affect prognosis in HF, including low LVEF, pulmonary disease and renal disease which are common among older patients.

In addition, a single biomarker is not always sufficient for risk assessment in an older population with $\mathrm{HF}$, where comorbidity is common. Consequently, there is a need for applying a multimarker strategy that can provide adequate risk assessment. Horwich et al studied 238 patients (mean age 53 years) with advanced $\mathrm{HF}$ who had been referred for cardiac transplantation evaluation. They found that the level of cardiac troponin I combined with the level of BNP improved the prediction of all cause deaths or an urgent need for cardiac transplantation. ${ }^{20}$ Ishino et al studied 164 patients with HF (mean age 68 years old). They reported that the combined levels of BNP, heart-type fatty acid-binding protein and pentraxin three could improve the prediction of cardiac death or hospitalisation because of worsening of $\mathrm{HF}^{19}$ However, there are only a limited number of studies using a multimarker strategy for prognostic assessment in older patients with HF.

In this study, we developed a composite risk score based on age, TnT and CysC levels, biomarkers known to have prognostic value for patients with HF. ${ }^{20} 21$ This composite risk score was able to differentiate older patients with HF into high-risk and low-risk groups. The score was particularly useful among older patients with HF who had moderately elevated NTproBNP, a group that is often difficult to evaluate. We suggest that this composite risk score should be used as a prognostic algorithm for older patients with $\mathrm{HF}$ that have NTproBNP levels in the range 2000-8000 ng/l. However, it is possible to use the score at all NTproBNP levels.

However, the score must be validated in an independent and larger cohort before it can safely be implemented in clinical routine. The sample size is also rather small so the results should be interpreted with caution.

It is already established that renal function, $\operatorname{TnT}$ as well as age can provide independent prognostic information, but our study focuses on how these markers can be dichotomised and combined into a simple prognostic scoring algorithm that is memoriseable and easily applied by busy clinicians. Successful therapeutic intervention could possibly lead to decreasing levels of TnT and CysC. This could generate fewer points in the prognostic score and thus imply a better prognosis, something that has to be evaluated in a future study.

In this exploratory study we chose to include a sample size of 131 patients to be able to test multiple biomarkers at a reasonable cost and generate useful hypotheses for future research. We chose to study all-cause mortality because it is robust and not prone to reporting bias. We also believe that all-cause mortality is more important in the elderly since they can diebecause of non-cardiac reasons.

In conclusion, by assessing multiple biomarkers at discharge, our data suggest that, when NTproBNP levels are between 2000 and $8000 \mathrm{ng} / \mathrm{l}$, a composite risk factor score that includes the levels of TnT, CysC and age provided superior risk stratification for mortality compared with NTproBNP alone.

Acknowledgements We are thankful for the expertise and analysis of the laboratory parameters by the staff at the department of clinical chemistry at Sahlgrenska University Hospital.

Contributors The five authors are justifiably credited with authorship, according to the authorship criteria. CB was involved in conception, design, acquisition of data, analysis and interpretation of data, drafting of the manuscript, final approval; $\mathrm{JJ}$ in design, acquisition of data, final approval given; MP in analysis and interpretation of data; $\mathrm{OH}$ in interpretation of data, drafting of the manuscript, final approval; and MF in conception, design, interpretation of data, drafting of the manuscript and final approval. 
Funding This work was supported by the Swedish Cancer Society $(\mathrm{OH})$, Swedish Research Council $(\mathrm{OH})$, Swedish Pain Foundation $(\mathrm{OH})$, the Sahlgrenska University Hospital Research Foundation (MLXF, OH), Swedish Heart-Lung Foundation (MLXF), Sahlgrenska University Hospital Research Foundation (MLXF) and Vetenskapliga rådet in Halland (CB).

Competing interests None.

Ethics approval The study protocol was approved by the Ethical Committee at the University of Gothenburg. Written informed consent was obtained from all patients, and the study protocol conformed to the ethical guidelines of the 1975 Declaration of Helsinki.

Provenance and peer review Not commissioned; externally peer reviewed.

Data sharing statement There are no additional data available.

\section{REFERENCES}

1. Askoxylakis V, Thieke C, Pleger ST, et al. Long-term survival of cancer patients compared to heart failure and stroke: a systematic review. BMC Cancer 2010;10:105.

2. Hoyert DL, Heron MP, Murphy SL, et al. Deaths: final data for 2003. Natl Vital Stat Rep 2006;54:1-120.

3. Roger VL, Go AS, Lloyd-Jones DM, et al. Heart disease and stroke statistics-2012 update: a report from the American heart association. Circulation 2012;125:188-97.

4. Murray CJ, Lopez AD. Mortality by cause for eight regions of the world: global Burden of disease study. Lancet 1997;349:1269-76.

5. Mogensen UM, Ersboll M, Andersen M, et al. Clinical characteristics and major comorbidities in heart failure patients more than 85 years of age compared with younger age groups. Eur $J$ Heart Fail 2011;13:1216-23.

6. van der Wel MC, Jansen RW, Bakx JC, et al. Non-cardiovascular co-morbidity in elderly patients with heart failure outnumbers cardiovascular co-morbidity. Eur J Heart Fail 2007;9:709-15.

7. Formiga F, Chivite D, Manito N, et al. One-year follow-up of heart failure patients after their first admission. QJM 2004;97:81-6.

8. Lien CT, Gillespie ND, Struthers AD, et al. Heart failure in frail elderly patients: diagnostic difficulties, co-morbidities, polypharmacy and treatment dilemmas. Eur J Heart Fail 2002:4:91-8.
9. Pocock SJ, Wang D, Pfeffer MA, et al. Predictors of mortality and morbidity in patients with chronic heart failure. Eur Heart $J$ 2006;27:65-75.

10. Levy WC, Mozaffarian D, Linker DT, et al. The Seattle heart failure model: prediction of survival in heart failure. Circulation 2006;113:1424-33.

11. Yamasaki $\mathrm{N}$, Kitaoka $\mathrm{H}$, Matsumura $\mathrm{Y}$, et al. Heart failure in the elderly. Intern Med 2003;42:383-8.

12. Ho KK, Pinsky JL, Kannel WB, et al. The epidemiology of heart failure: the Framingham study. J Am Coll Cardiol 1993;22:6A-13A.

13. Heiat A, Gross CP, Krumholz HM. Representation of the elderly, women, and minorities in heart failure clinical trials. Arch Intern Med 2002;162:1682-8

14. Doust JA, Pietrzak E, Dobson A, et al. How well does B-type natriuretic peptide predict death and cardiac events in patients with heart failure: systematic review. BMJ 2005;330:625.

15. Andersson SE, Edvinsson ML, Bjork J, et al. High NTproBNP is a strong predictor of outcome in elderly heart failure patients. $A m \mathrm{~J}$ Geriatr Cardiol 2008;17:13-20.

16. McMurray JJ, Adamopoulos S, Anker SD, et al. ESC Guidelines for the diagnosis and treatment of acute and chronic heart failure 2012: the task force for the diagnosis and treatment of acute and chronic heart failure 2012 of the European society of cardiology. Developed in collaboration with the Heart Failure Association (HFA) of the ESC Eur Heart J 2012;33:1787-847.

17. Bouvy ML, Heerdink ER, Leufkens HG, et al. Predicting mortality in patients with heart failure: a pragmatic approach. Heart 2003;89: 605-9.

18. Bohm M, Voors AA, Ketelslegers JM, et al. Biomarkers: optimizing treatment guidance in heart failure. Clin Res Cardiol 2011;100:973-81.

19. Ishino M, Takeishi Y, Niizeki T, et al. Risk stratification of chronic heart failure patients by multiple biomarkers: implications of BNP, H-FABP, and PTX3. Circ J 2008;72:1800-5.

20. Horwich TB, Patel J, MacLellan WR, et al. Cardiac troponin I is associated with impaired hemodynamics, progressive left ventricular dysfunction, and increased mortality rates in advanced heart failure. Circulation 2003;108:833-8.

21. Jensen J, Ma LP, Bjurman C, et al. Prognostic values of NTpro BNP/BNP ratio in comparison with NTpro BNP or BNP alone in elderly patients with chronic heart failure in a 2-year follow up. Int $J$ Cardiol 2012;155:1-5. 